\title{
Caveolin-1 regulates osteoclast differentiation by suppressing cFms degradation
}

\author{
Yong Deok Lee ${ }^{1}$, Soo-Hyun Yoon ${ }^{1}$, Eunhee $\mathrm{Ji}^{2}$ and Hong-Hee Kim ${ }^{1}$ \\ Caveolae are flask-shaped cell-surface membranes, which consist of cholesterol, sphingolipids and caveolin proteins. In a \\ microarray analysis, we found that caveolin-1 (Cav-1) was upregulated by receptor activator of NFKB ligand (RANKL), the \\ osteoclast differentiation factor. Silencing of Cav-1 inhibited osteoclastogenesis and also decreased the activation of mitogen- \\ activated protein kinase and the induction of NFATc 1 by RANKL. Cav-1 knockdown suppressed the expression of cFms and \\ RANK, two major receptors for osteoclastogenesis. Interestingly, cFms expression was decreased only at the protein level, not at \\ the messenger RNA (mRNA) level, whereas RANK expression was decreased at both the mRNA and protein levels. Furthermore, \\ Cav-1 deficiency increased the lysosomal degradation of cFms. Taken together, these results demonstrate that Cav-1-dependent \\ cFms stabilization contributes to efficient osteoclastogenesis.
}

Experimental \& Molecular Medicine (2015) 47, e192; doi:10.1038/emm.2015.77; published online 30 October 2015

\section{INTRODUCTION}

Bone homeostasis is tightly controlled by two types of cells, called osteoclasts and osteoblasts. Therefore, the imbalance between osteoclast and osteoblast activities gives rise to various bone diseases. Osteoclasts are specialized cells for bone resorption and are derived from hematopoietic stem cells. Osteoclast differentiation is dependent on the macrophage colonystimulating factor (M-CSF) and the receptor activator of NFKB ligand (RANKL). ${ }^{1}$ RANKL stimulates the activation of extracellular signal-regulated kinases 1 and 2 (ERK1/2), p38 and c-Jun N-terminal kinase (JNK) ${ }^{1,2}$ after the recruitment of TNF receptor-associated factor 6 (TRAF6), a key adaptor protein, ${ }^{3}$ to the receptor activator of NFKB (RANK). Ultimately, these signals activate the nuclear factor of activated T-cells, cytoplasmic 1 (NFATc1), the master transcription factor of osteoclastogenesis. ${ }^{1,4}$ NFATc1, in cooperation with microphthalmia-associated transcription factor and PU.1, facilitates the transcription of genes for tartrate-resistant acid phosphatase, matrix metalloproteinases, and cathepsin K enzymes, which are important for osteoclast functions. ${ }^{5,6}$

Caveolae, a specialized type of lipid rafts, are comprised of cholesterol, sphingolipids and three isoforms of caveolin proteins. $^{7}$ Cav-1 and Cav-2 are expressed ubiquitously with abundancy in fibroblasts, endothelial cells and epithelial cells. Cav-3 is detected only in muscle cells. ${ }^{8}$ Among the three isoforms, Cav-1 is the major protein of caveolae. ${ }^{9}$ Cav-1 interacts with cholesterol, which is important for membrane microdomain stability. ${ }^{7}$ Like lipid rafts, caveolae have several roles in cellular processes such as endocytosis, trafficking and signal transduction. For example, interleukin-1 beta (IL-1 $\beta$ ) induces NFKB activation through the Cav-1-dependent endocytosis of NAPDH oxidase 2 and IL- $\beta \mathrm{R} 1 .{ }^{10} \mathrm{Cav}-1$ interacts with the glucagon-like peptide 1 receptor and regulates its localization to the plasma membrane. ${ }^{11}$ Cav-1 also regulates calcium signaling through interaction with the Goq protein. ${ }^{12}$ Disruption of caveolae decreased the vitamin D3-dependent activation of mitogen-activated protein kinase (MAPK) and Src. ${ }^{13}$

In previous reports, Cav-1 has been shown to have several roles in macrophages. Cav-1 mediated the anti-inflammatory effect via the MAPK kinase 3/p38 pathway. ${ }^{14}$ Loss of Cav-1 reduced the expression of CD14, CD36, TLR4 and MYD88, which prevented phagocytosis and the production of inflammatory cytokines. ${ }^{15}$ Cav-1 also has an essential role in the differentiation of monocytes into macrophages. ${ }^{16}$

In our recent study, we found that Cav-1 was involved in the regulation of osteoclast differentiation and that $\mathrm{Cav}-1^{-1-}$ female mice had higher bone mass than the wild-type mice. ${ }^{17}$ In the present study, we further investigated the role of Cav-1 in osteoclastogenesis and in the regulation of RANK and cFms, the M-CSF receptor.

\footnotetext{
${ }^{1}$ Department of Cell and Developmental Biology, BK21 Program and Dental Research Institute, Seoul National University, Seoul, Korea and ${ }^{2}$ College of Pharmacy, Gachon University, Incheon, Korea

Correspondence: Professor H-H Kim, Department of Cell and Developmental Biology, BK21 Program and Dental Research Institute, Seoul National University, 28 Yeongon-Dong, Chongno-Gu, Seoul 110-749, Korea.

E-mail: hhbkim@snu.ac.kr
}

Received 5 June 2015; revised 22 July 2015; accepted 29 July 2015 


\section{MATERIALS AND METHODS}

\section{Reagents and antibodies}

Anti-NFATc1 was purchased from Santa Cruz Biotechnology (Santa Cruz, CA, USA). Anti-RANK was purchased from Abcam (Cambridge, UK). Anti-Cav-1, cFms and other antibodies were purchased from Cell Signaling Technology (Beverly, MA, USA). Lipofectamine 2000 was purchased from Invitrogen (Carlsbad, CA, USA). Human soluble RANKL and M-CSF were purchased from Pepro-Tech (Rocky Hill, NJ, USA). MG132 and $\gamma$-secretase inhibitor were purchased from Sigma (St Louis, MO, USA).

\section{Microarray}

Bone marrow-derived macrophages (BMMs) from 5-week-old female mice were grown in $\alpha$-MEM with M-CSF $\left(30 \mathrm{ng} \mathrm{ml}^{-1}\right)$ and RANKL $\left(200 \mathrm{ng} \mathrm{ml}^{-1}\right.$ ). Total RNA was prepared from untreated cells (day 0 ) and cells treated with RANKL (day 2) and reverse transcribed into cRNA. The cRNAs were then hybridized with the Mouse WG-6 v2.0 BeadChips, each of which contained $>45000$ probes per array (Illumina, San Diego, CA, USA). Microarray data were analyzed with Genome Studio Gene Expression Module (Gx) v3.2 (Illumina).

\section{In vitro osteoclast differentiation}

BMMs were generated using 5-week-old female ICR mice. Flushed bone marrow cells from long bones were plated with $\alpha$-MEM containing $10 \%$ FBS and $1 \%$ antibiotics in culture dishes. After $24 \mathrm{~h}$, non-adherent cells were further incubated on petri dishes in $\alpha$-MEM containing $10 \%$ FBS and $1 \%$ antibiotics with M-CSF $\left(30 \mathrm{ng} \mathrm{m}^{-1}\right)$ for 3 days. Adherent cells (BMMs) were used for osteoclastogenesis by culturing them with M-CSF $\left(30 \mathrm{ng} \mathrm{ml}^{-1}\right)$ and RANKL $\left(200 \mathrm{ng} \mathrm{ml}^{-1}\right.$ ) in $\alpha$-MEM containing $10 \%$ FBS and $1 \%$ antibiotics for 4 days.

\section{In vitro tartrate-resistant acid phosphatase staining}

To determine osteoclast differentiation, cells were fixed in $3.7 \%$ formaldehyde solution and permeabilized with $0.1 \%$ Triton X-100. After being washed twice with phosphate-buffered saline, the cells were stained using a Leukocyte Acid Phosphatase Assay Kit from Sigma according to the manufacturer's instructions. Tartrate-resistant acid phosphatase -positive cells containing more than three nuclei were considered to be differentiated osteoclasts.

\section{Real-time reverse transcriptase polymerase chain reaction} Total RNA was extracted using TRIzol reagent (Invitrogen). Then, cDNA synthesis was performed using Superscript II reverse transcriptase (Invitrogen) according to the manufacturer's instructions. Gene expression levels were analyzed with target gene specific primers listed in Table 1 using an ABI 7500 instrument and SYBR Green Master Mix reagents

\section{Western blotting}

Cells were lysed in RIPA buffer (50 mm Tris-HCl, $\mathrm{pH}$ 8.0, $150 \mathrm{~mm}$ $\mathrm{NaCl}, 1 \%$ NP-40, 0.5\% sodium deoxycholate, $0.1 \%$ SDS, $0.5 \mathrm{~mm}$ PMSF, proteinase inhibitor cocktail (Roche, Mannheim, Germany), $100 \mathrm{~mm}$ sodium vanadate, $0.5 \mathrm{~m}$ sodium fluoride) and centrifuged at 14000 r.p.m. for $15 \mathrm{~min}$ at $4{ }^{\circ} \mathrm{C}$. After protein quantification, cell extracts were separated on polyacrylamide gels and transferred onto nitrocellulose membranes. After being blocked with 5\% skim milk for $1 \mathrm{~h}$, the membranes were incubated with the primary antibody at $4{ }^{\circ} \mathrm{C}$ overnight. The next day, the membranes were incubated with the
Table 1 List of primer sequences

\begin{tabular}{lll}
\hline Name & $5^{\prime}-3^{\prime}$ & Sequences \\
\hline NFATc1 & Forward & CCAGTATACCAGCTCTGCCA \\
& Reverse & GTGGGAAGTCAGAAGTGGT \\
RANK & Forward & AGAAGACGGTGCTGGAGCT \\
& Reverse & TAGGAGCAGTGAACCAGTCG \\
cFms & Forward & CTTCACTCCGGTGGTGGGG \\
& Reverse & GCGCACCTGGTACTTCGGCT \\
Cav-1 & Forward & TATGACGCGCACACCAAGGA \\
& Reverse & GCCCAGATGTGCAGGAAGGA \\
Ctsk & Forward & ATATGTGGGCCACCATGAAAGTT \\
& Reverse & TCGTTCCCACAGGAATCTCT \\
MMP9 & Forward & GACGGCACGCCTTGGTGAG \\
& Reverse & AGGAGCGGCCTCAAAGATG \\
B-Actin & Forward & TCTGGCACCACACCTTCTAC \\
& Reverse & TACGACCAGAGGCATACAGG \\
\hline
\end{tabular}

Abbreviation: RANK, receptor activator of NFKB.

horseradish peroxidase-conjugated secondary antibody, and immune complexes were detected using enhanced chemiluminescence reagents.

\section{Cav-1 knockdown by small interfering RNA}

We designed Cav-1-specific small interfering RNA (siRNA) using the siRNA design program provided by Invitrogen. BMMs were transfected with siRNA (40 nM) using Lipofectamine 2000 (Invitrogen) according to the manufacturer's instructions.

\section{Bromodeoxyuridine incorporation assay}

The incorporation of bromodeoxyuridine into cells was measured using the bromodeoxyuridine Cell Proliferation Assay Kit from Calbiochem (San Diego, CA, USA) according to the manufacturer's instructions.

\section{Terminal deoxynucleotidyl transferase dUTP nick end labeling assay}

TUNEL (terminal deoxynucleotidyl transferase dUTP nick end labeling) assays were performed using an In Situ Cell Death Detection Kit (Roche) according to the manufacturer's instructions.

\section{Flow cytometry}

To detect the surface expression of cFms, cells were incubated with cFms antibody for $20 \mathrm{~min}$ on ice. Cells were then washed with phosphate-buffered saline and incubated with a fluorescein isothiocyanate-conjugated secondary antibody for $20 \mathrm{~min}$. Flow cytometry analysis was performed using a fluorescence-activated cell sorting Calibur flow cytometer (Becton Dickinson, Franklin Lakes, NJ, USA).

\section{Immunofluorescence staining}

Cells were fixed with $3.7 \%$ formaldehyde and permeabilized with $0.1 \%$ Triton X-100. The permeabilized cells were then blocked with $1 \%$ bovine serum albumin in phosphate-buffered saline, incubated with a primary antibody at $4{ }^{\circ} \mathrm{C}$ overnight, and washed three times with phosphate-buffered saline for $5 \mathrm{~min}$ per wash. Next, the cells were incubated with a secondary antibody for $2 \mathrm{~h}$ at room temperature. Finally, the cells were observed under a Zeiss LSM 5 
PASCAL laser-scanning microscope (Carl Zeiss Microimaging GmbH, Goettingen, Germany) with $\times 400$ magnification (C-Apochromat/1.2 WCorr).

\section{Statistical analysis}

In all the quantitative experiments, data are presented as the means \pm s.d. Student's paired $t$-test was performed to determine the significance of the differences between the indicated samples.

\section{RESULTS}

\section{Cav-1 upregulation by RANKL is required for} osteoclastogenesis

To find novel factors that influence the differentiation of osteoclasts, we performed a cDNA microarray analysis. Mouse BMMs were used as precursor cells, and the cells were cultured in the presence or absence of RANKL, the osteoclast differentiation factor. Among the differentially expressed genes, we found that Cav-1 was upregulated by RANKL treatment (Figure 1a). The extent of Cav-1 upregulation was much stronger than that of matrix metalloproteinase 9 or cathepsin $\mathrm{K}$, the known osteoclast-marker genes (Figure 1a). The increase in Cav-1 mRNA expression was confirmed by real-time PCR experiments (Figure 1b). We next explored the possibility of Cav-1 involvement in RANKL-induced osteoclast differentiation by evaluating the effect of blocking Cav-1 upregulation on osteoclastogenesis. To this end, BMMs were transfected with siRNA oligonucleotides against Cav-1 and then cultured in the presence of M-CSF and RANKL for 4 days. Under the conditions, Cav-1 upregulation was efficiently suppressed (Figure 1c). The siRNA-mediated Cav-1 knockdown significantly reduced the generation of osteoclasts as assessed by counting tartrate-resistant acid phosphatase -positive multinuclear cells (Figure 1d). This result was consistent with our recent report that showed inhibitory effect of Cav-1 siRNA, but not Cav-2 siRNA, on osteoclast formation. ${ }^{17}$ Given that the elevation in NFATc1 expression is essential for osteoclastogenesis, ${ }^{1}$ we examined the effect of Cav-1 knockdown on NFATc1 level. The RANKL-induced mRNA expression of NFATc1 was attenuated by Cav-1 knockdown (Figure 1e). Collectively, these results suggest that Cav-1 upregulation by RANKL has a positive role for osteoclastogenesis. a

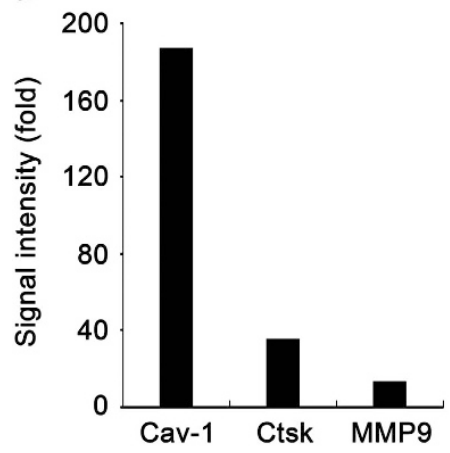

C

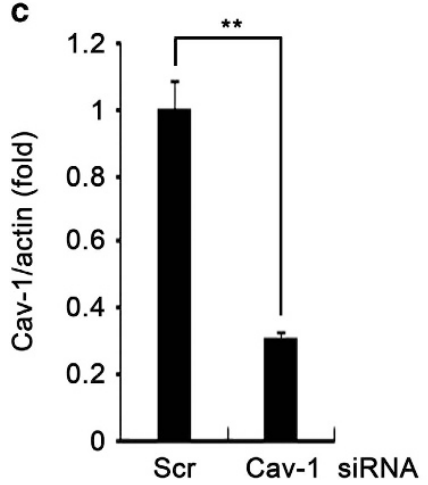

b
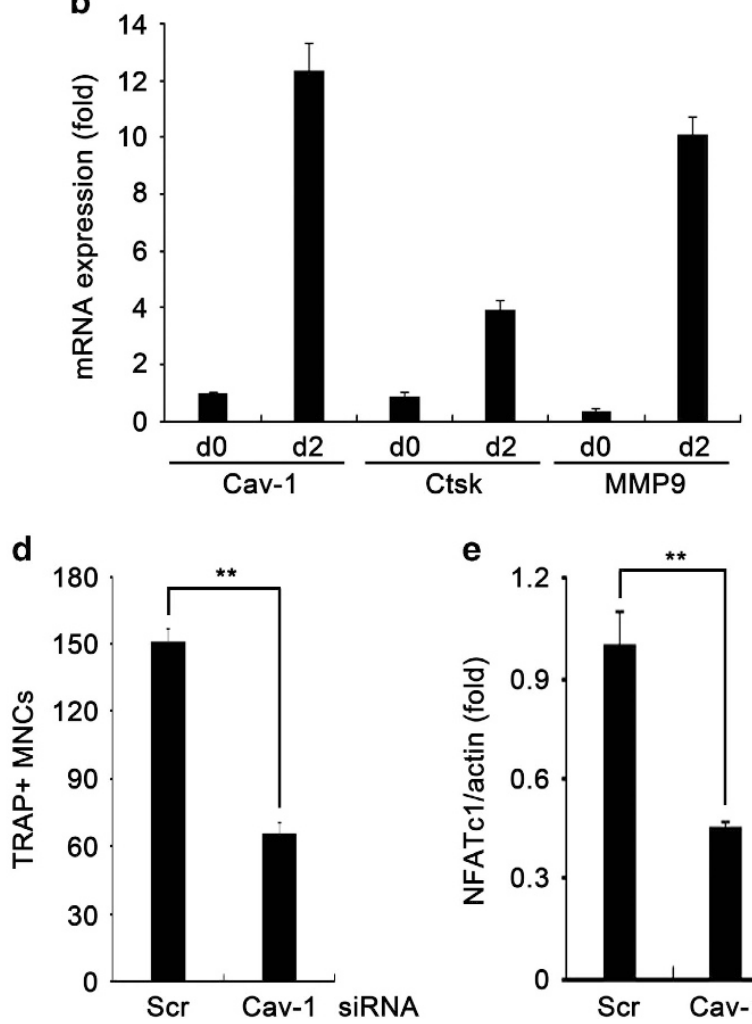

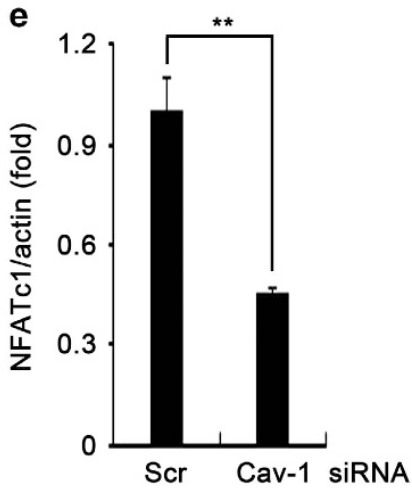

Figure 1 Cav-1 induction positively regulated osteoclast differentiation. (a) BMMs were treated with $\mathrm{M}-\mathrm{CSF}\left(30 \mathrm{ng} \mathrm{ml}^{-1}\right.$ ) and RANKL $\left(200 \mathrm{ng} \mathrm{ml}^{-1}\right.$ ) for 2 days. The mRNA expression for Cav-1 was analyzed by microarray. (b) BMMs were treated with $\mathrm{M}-\mathrm{CSF}$ ( $30 \mathrm{ng} \mathrm{ml}^{-1}$ ) and RANKL (200 $\mathrm{ng} \mathrm{ml}^{-1}$ ) for 2 days. mRNA expression of Cav-1, Ctsk, MMP9 was analyzed by real-time PCR. (c) BMMs transfected with siRNA oligonucleotides were incubated with M-CSF $\left(30 \mathrm{ng} \mathrm{ml}^{-1}\right)$ and RANKL $\left(200 \mathrm{ng} \mathrm{ml}^{-1}\right)$ for 2 days. The mRNA level of Cav-1 was analyzed by real-time PCR. (d) Cells were treated as in $\mathbf{c}$ and stained for tartrate-resistant acid phosphatase (TRAP). TRAP-positive multinucleated cells were counted. (e) Cells were treated as in c. The mRNA level of NFATc1 was analyzed by real-time PCR. ${ }^{* *} P<0.005$ as compared with controls. BMM, bone marrow-derived macrophage; Cav-1, Cav-1 siRNA; M-CSF, macrophage colony-stimulating factor; mRNA, messenger RNA; RANKL, receptor activator of NFKB ligand; Scr, control siRNA; siRNA, small interfering RNA. 
Cav-1 knockdown affected the proliferation, apoptosis and migration of osteoclast precursors

Differences in cell numbers during culturing will affect the number of osteoclasts generated. Therefore, we examined whether the Cav-1 knockdown had any effect on cell proliferation. The proliferation of BMMs was not affected by Cav-1 knockdown when cells were cultured with M-CSF only (Figure 2a). However, it was inhibited by Cav-1 knockdown when RANKL was also present (Figure $2 \mathrm{a}$ ). As previous reports have implicated Cav-1 in cell survival, ${ }^{18,19}$ we next evaluated the effect of Cav-1 on the apoptosis of osteoclast precursor cells. BMMs with silenced Cav-1 showed increased TUNELpositive cells as compared with the control siRNA-transfected BMMs (Figure 2b). Pre-fusion osteoclasts, cultured for 2 days in the presence of RANKL, also showed higher TUNELpositivity in the Cav-1 silenced cells (Figure 2b). In addition, we examined whether Cav-1 knockdown modulates the level of cyclin D1 and cleaved poly(ADP ribose) polymerase, the a

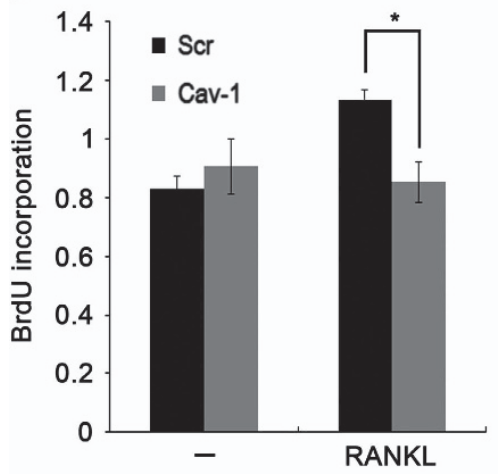

C

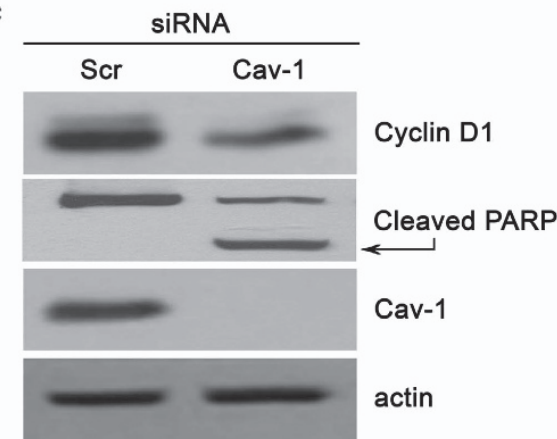

b
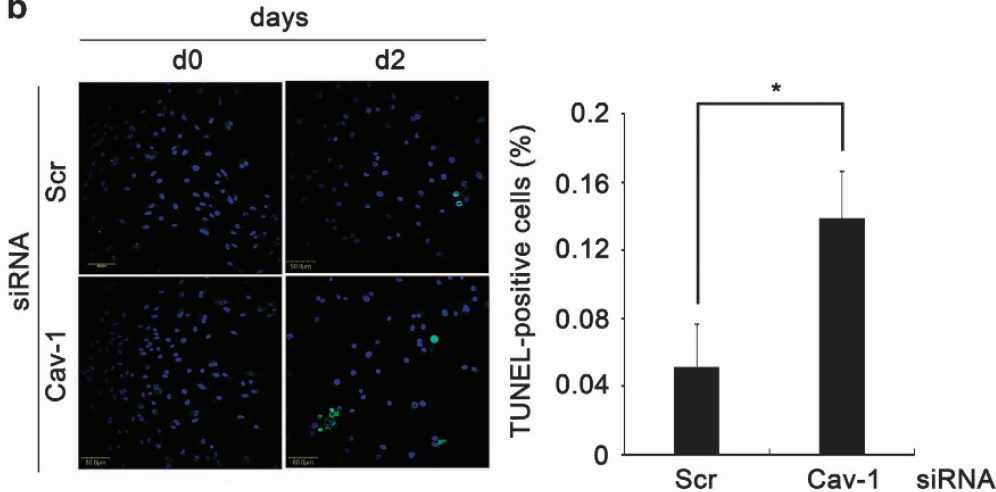

d

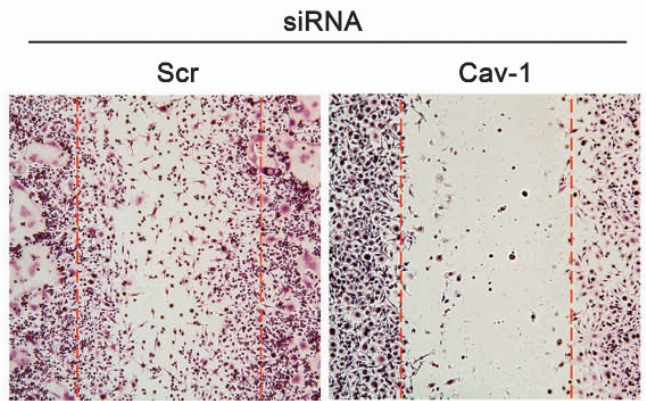

e
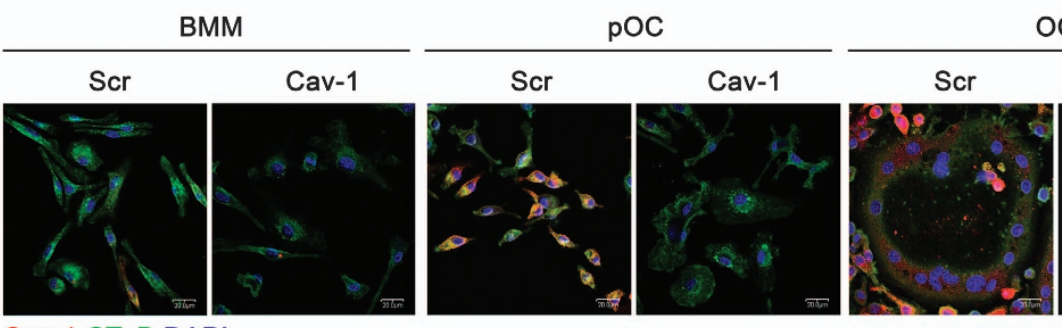

OC

Cav-1 siRNA

Figure 2 The viability and morphology of osteoclast precursor cells were affected by Cav-1 knockdown. BMMs were transfected with control or Cav-1 siRNA for $24 \mathrm{~h}$. (a) BMMs with silenced Cav-1 that were treated with M-CSF (30 ng ml-1) with or without RANKL (200 $\mathrm{ng} \mathrm{ml}^{-1}$ ) for 2 days were incubated with bromodeoxyuridine (BrdU) for $2 \mathrm{~h}$. BrdU incorporation was determined by ELISA. (b) TUNEL assay was performed with control or Cav-1 siRNA-transfected BMMs after treatment with M-CSF (30 ng ml-1) and RANKL (200 ng ml-1) for 2 days. TUNEL-positive cells were counted on day 2. (c) BMMs were treated with M-CSF (30 ng ml-1) and RANKL (200 ng ml-1) for 2 days. Cyclin D1 and cleaved poly(ADP ribose) polymerase (PARP) were determined by western blotting. (d) For the migration assay, BMMs were cultured with M-CSF (30 $\mathrm{ng} \mathrm{ml}^{-1}$ ) to reach $70 \sim 80 \%$ confluence as a monolayer. The monolayer was gently scratched, and cells were incubated for $12 \mathrm{~h}$. (e) Cells were incubated with M-CSF (30 ng ml-1) and RANKL (200 ng ml-1) for 2 days (pOC, pre-fusion osteoclasts) or 4 days (OC, osteoclasts). Cells were immunostained using an antibody for Cav-1 followed by incubation with a Cy3conjugated secondary antibody. Membranes were stained with fluorescein isothiocyanate (FITC)-conjugated CTxB. The nuclei were stained with DAPI. ${ }^{*} P<0.05$ as compared with controls. BMM, bone marrow-derived macrophage; Cav-1, Cav-1 siRNA; ELISA, enzyme-linked immunosorbent assay; M-CSF, macrophage colony-stimulating factor; RANKL, receptor activator of NFKB ligand; Scr, control siRNA; siRNA, small interfering RNA; TUNEL, terminal deoxynucleotidyl transferase dUTP nick end labeling. 
indicators of cell proliferation and apoptosis, respectively. Cav1 knockdown significantly reduced cyclin D1 levels and increased poly(ADP ribose) polymerase cleavage (Figure 2c). Cav-1 has also been implicated in cell migration and morphology. ${ }^{20}$ As shown in Figure 2d, Cav-1 knockdown strongly inhibited the migratory activity of the BMMs. We also found that the BMMs with silenced Cav-1 showed abnormal morphology. The pre-fusion osteoclasts with silenced Cav-1 showed a flattened morphology, and the ring-like membrane structure of the mature osteoclasts was disrupted (Figure 2e).
M-CSF- and RANKL-induced signaling pathways were inhibited by Cav-1 knockdown

To explore the mechanism for the anti-osteoclastogenic effect of Cav-1 siRNA, we examined the effect of Cav-1 knockdown on the M-CSF and RANKL signaling pathways. As the MAPK signaling pathways are activated by M-CSF and RANKL, ${ }^{21}$ and the Akt pathway is crucial for cell survival, we investigated these signaling pathways. When the cells transfected with Cav-1 siRNA were stimulated with M-CSF, the phosphorylation of p38, ERK1/2 and Akt was inhibited as compared with the control siRNA-transfected BMMs (Figure 3a).
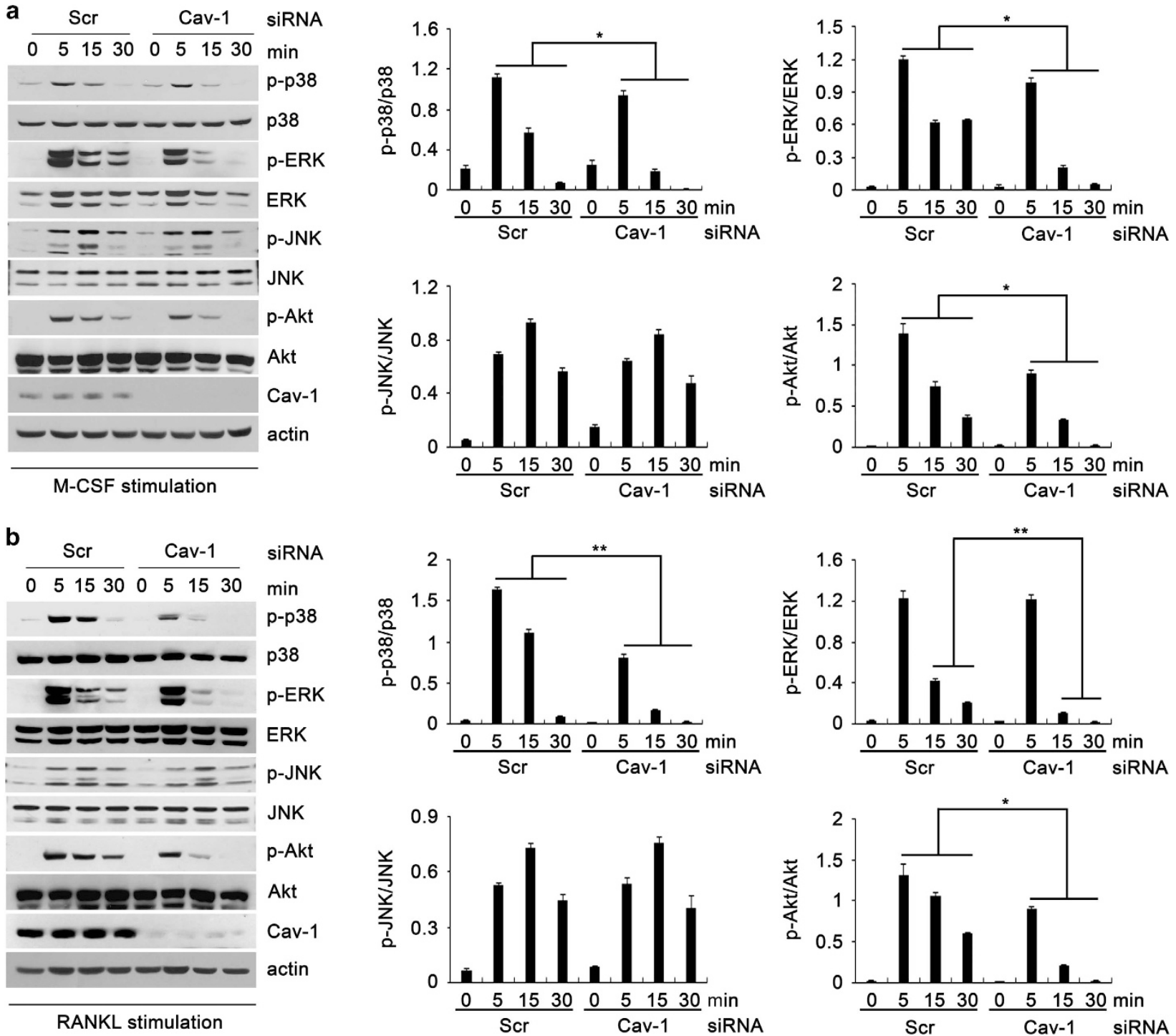

Figure 3 Cav-1 knockdown disrupted MAPK and Akt signaling. (a) BMMs were transfected with control or Cav-1 siRNA for $24 \mathrm{~h}$. After serum starvation for $6 \mathrm{~h}$, cells were treated with M-CSF $\left(90 \mathrm{ng} \mathrm{ml}^{-1}\right)$. The phosphorylation of ERK, p38, JNK and Akt was determined by western blotting. The relative band intensities were quantified by densitometry. (b) BMMs were transfected with control or Cav-1 siRNA for $24 \mathrm{~h}$. Cells were treated with RANKL $\left(400 \mathrm{ng} \mathrm{ml}^{-1}\right)$ after serum starvation for $6 \mathrm{~h}$. The phosphorylation of ERK, p38, JNK and Akt was determined by western blotting. The relative band intensities were quantified by densitometry. ${ }^{*} P<0.05 ;{ }^{* *} P<0.005$ as compared with controls. BMM, bone marrow-derived macrophage; Cav-1, Cav-1 siRNA; MAPK, mitogen-activated protein kinase; M-CSF, macrophage colony-stimulating factor; RANKL, receptor activator of NFKB ligand; Scr, control siRNA; siRNA, small interfering RNA. 
The RANKL-stimulated phosphorylation of p38, ERK1/2 and Akt was also significantly attenuated in the BMMs with silenced Cav-1 (Figure 3b). These data indicate that the presence of Cav-1 is required for the effective signaling of both M-CSF and RANKL in osteoclastogenesis.

\section{Cav-1 knockdown inhibited the expression of cFms and RANK}

As the M-CSF- and RANKL-triggered signaling pathways were downregulated by Cav-1 knockdown, we examined the expression levels of the cytokine receptors. The protein levels of cFms (the M-CSF receptor) and RANK were markedly reduced by Cav-1 knockdown during osteoclastogenesis (Figure 4a). Interestingly, the mRNA level of cFms was not affected by Cav-1 knockdown (Figure 4b). In contrast, the RANK mRNA level was markedly reduced by Cav-1 knockdown (Figure 4b). The immunofluorescence staining showed that the cFms level in the cell periphery region was also reduced by Cav-1 knockdown (Figure 4c). In addition, the fluorescence-activated cell sorting analysis supported the reduction of cell surface $\mathrm{cFms}$ proteins by Cav-1 knockdown (Figure 4d). Diverse membrane proteins were found in the caveolae and were regulated by Cav-1dependent mechanisms. ${ }^{7,22}$ We examined whether cFms and RANK were localized in the caveolae. For caveolae isolation, we performed sucrose density gradient ultracentrifugation. ${ }^{23}$ The cFms and RANK proteins were found in the caveolae fractions of the pre-fusion osteoclasts (Figure 4e). We next tested whether Cav-1 interacted with cFms in pre-fusion osteoclasts. The immunoprecipitation of Cav-1 resulted in the coimmunoprecipitation of cFms, suggesting an interaction between the two proteins (Figure 4f). However, RANK was not co-immunoprecipitated with Cav-1 (Figure 4f). These
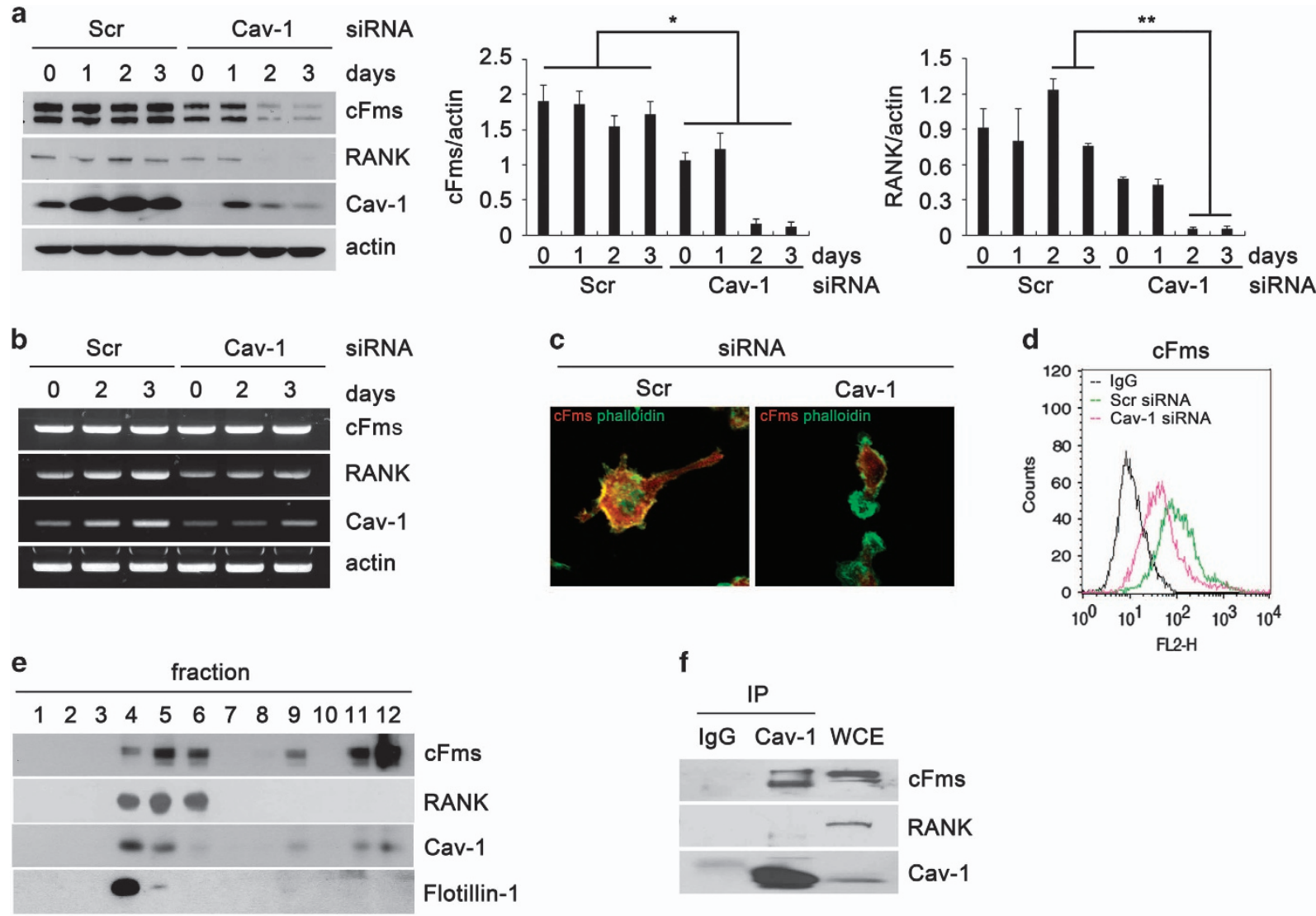

Figure 4 The cFms and RANK were downregulated by Cav-1 knockdown. BMMs were transfected with control or Cav-1 siRNA for $24 \mathrm{~h}$. (a) BMMs were treated with M-CSF $\left(30 \mathrm{ng} \mathrm{ml}^{-1}\right)$ and RANKL $\left(200 \mathrm{ng} \mathrm{ml}^{-1}\right)$ for the indicated number of days. Protein levels of $\mathrm{cFms}$, RANK and Cav-1 were determined by western blotting. The relative band intensities were quantified by densitometry. ${ }^{*} P<0.05$; ${ }^{* *} P<0.005$ as compared with controls. (b) The mRNA levels of cFms, RANK and Cav-1 were determined by PCR with reverse transcription. (c) Cells were immunostained with cFms antibody and Cy3-conjugated secondary antibody. Membranes were stained with fluorescein isothiocyanate (FITC)-conjugated phalloidin. (d) For the flow cytometry analyses, BMMs were incubated with cFms antibody, and were then incubated with FITC-conjugated secondary antibody. (e) BMMs were treated with M-CSF (30 ng ml-1) and RANKL $\left(200 \mathrm{ng} \mathrm{ml}^{-1}\right)$ for 2 days. Using sucrose density gradient ultracentrifugation, membrane proteins were isolated. Then, cFms, RANK and Cav-1 were detected by western blotting. Flotillin-1 was used as a membrane protein marker. (f) BMMs were treated with M-CSF $\left(30 \mathrm{ng} \mathrm{ml}^{-1}\right.$ ) and RANKL (200 $\mathrm{ng} \mathrm{ml}^{-1}$ ) for 2 days. Cell lysates were immunoprecipitated with IgG or Cav-1 antibody. The precipitates were subjected to western blotting. BMM, bone marrow-derived macrophage; Cav-1, Cav-1 siRNA; M-CSF, macrophage colony-stimulating factor; RANK, receptor activator of NFKB; RANKL, receptor activator of NFKB ligand; Scr, control siRNA; siRNA, small interfering RNA. 
results suggest that the caveolae structure differentially regulates the expression and subcellular localization of cFms and RANK.

\section{Cav-1 regulates the stability of cFms protein}

As Cav-1 knockdown reduced the cFms protein level without affecting its mRNA level, we next examined whether Cav-1 regulates cFms protein stability. When BMMs were treated with cycloheximide, a protein synthesis inhibitor, cFms was more rapidly degraded by Cav-1 silencing (Figure 5a). A similar pattern was observed with the RANK protein (Figure 5a). As diverse proteins are degraded via a ubiquitin-dependent mechanism, we investigated whether the inhibition of ubiquitin-dependent proteolysis could block the downregulation of cFms. BMMs were treated with MG132, and the cFms level was examined. As shown in Figure 5b, cFms downregulation was not suppressed by MG132 treatment
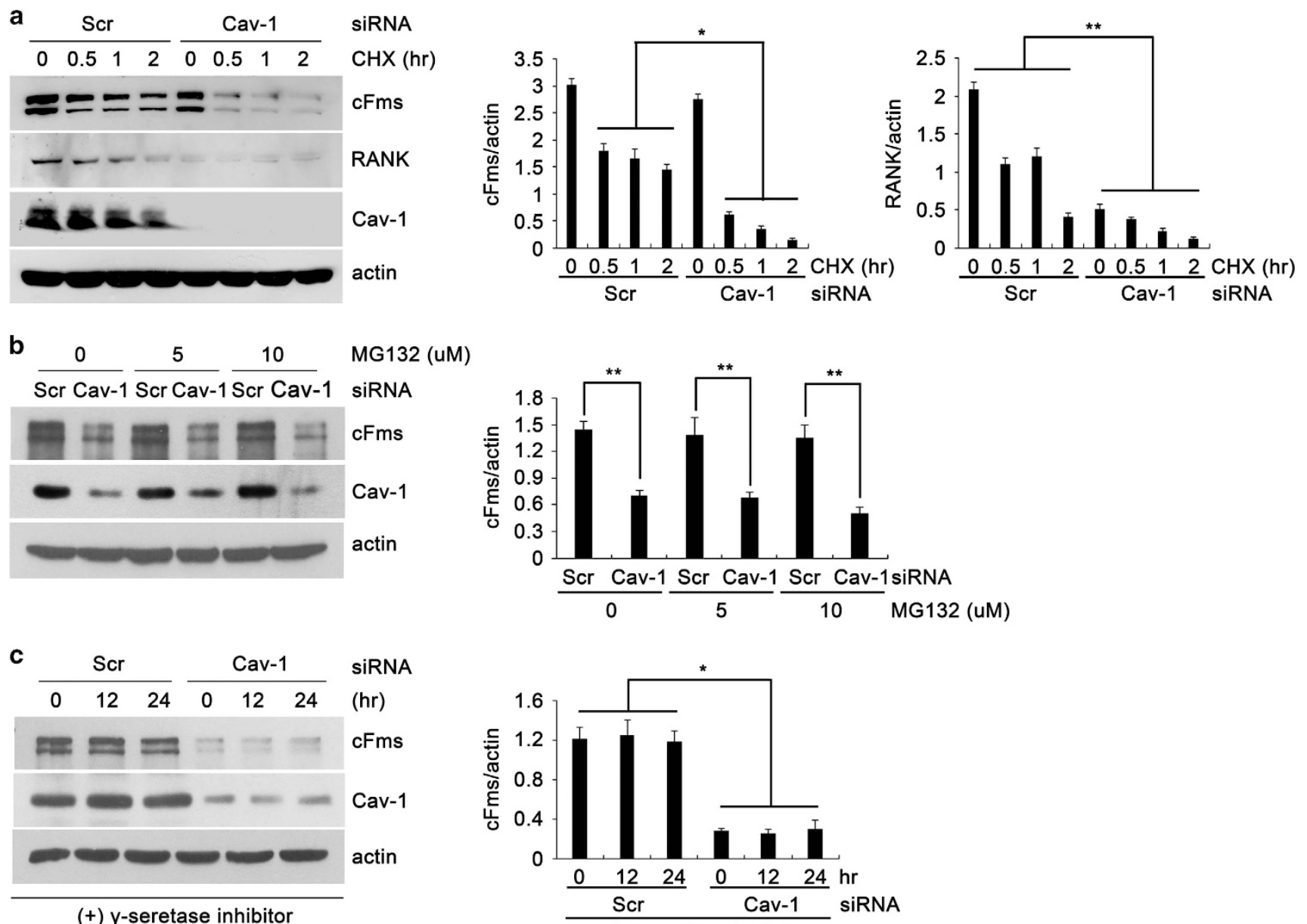

$(+)$ Y-seretase inhibitor

(+) Y-seretase inhibitor
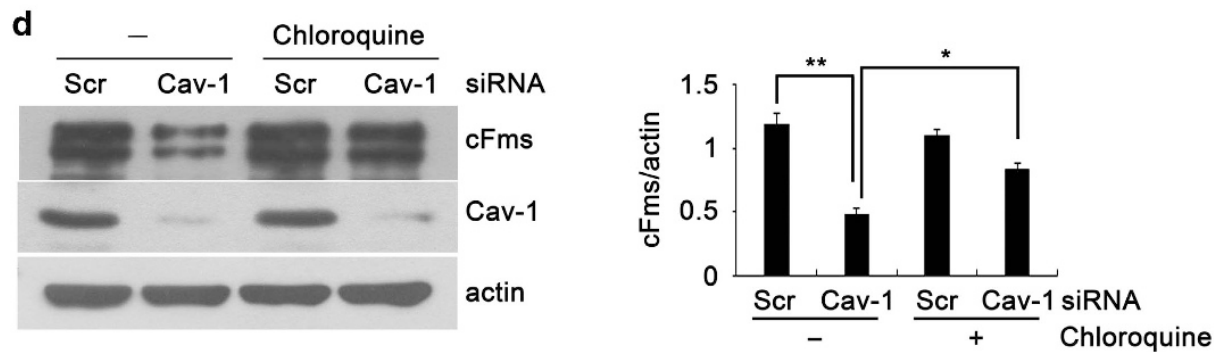

Figure 5 The cFms downregulation is mediated by lysosomal degradation. BMMs were transfected with control or Cav-1 siRNA. (a) Cells were treated with cycloheximide $\left(10 \mu \mathrm{g} \mathrm{ml}^{-1}\right)$ for the indicated time. The protein levels of cFms and RANK were determined by western blotting. (b) Cells were treated with MG-132 for $12 \mathrm{~h}$ at the indicated dosages. The protein level of cFms was determined by western blotting. (c) Cells were treated with $\gamma$-secretase inhibitor $\left(10 \mu \mathrm{g} \mathrm{ml} \mathrm{l}^{-1}\right)$ for the indicated time. The protein level of cFms was determined by western blotting. (d) Cells were treated with chloroquine $(10 \mu \mathrm{m})$ for $8 \mathrm{~h}$. The protein level of cFms was determined by western blotting. The relative band intensities were quantified by densitometry. ${ }^{*} P<0.05 ;{ }^{* *} P<0.005$ as compared with controls. BMM, bone marrow-derived macrophage; Cav-1, Cav-1 siRNA; RANK, receptor activator of NFKB; Scr, control siRNA; siRNA, small interfering RNA. 
(Figure 5b). Various membrane proteins were shown to undergo regulated intramembrane proteolysis, in which $\gamma$ secretase has been implicated. ${ }^{24}$ In previous reports, cFms was also shown to undergo the regulated intramembrane proteolysis process. ${ }^{25}$ To examine whether Cav-1 knockdown affects $\gamma$-secretase-mediated cFms proteolysis, BMMs were treated with $\gamma$-secretase inhibitor. However, the $\gamma$-secretase inhibitor treatment could not block the degradation of cFms (Figure 5c). The lysosomal degradation pathway has also been implicated in the regulation of protein levels. ${ }^{26,27}$ To investigate whether Cav-1 knockdown increases the lysosomal degradation of cFms, BMMs were treated with chloroquine, an inhibitor of lysosomal enzymes. Chloroquine markedly suppressed the downregulation of cFms (Figure $5 \mathrm{~d}$ ). These results suggest that lysosomal degradation, not ubiquitination, is related to Cav-1dependent cFms stability.

\section{DISCUSSION}

In this study, we found that Cav-1, the major component of caveolae, has a positive role in osteoclastogenesis. The disruption of caveolae by Cav-1 knockdown impaired osteoclast differentiation and inhibited the induction of NFATc1 (Figure 1), which was consistent with our recent report. ${ }^{17}$ In this study, we found additional roles of Cav-1 during osteoclastogenesis. The proliferation of BMMs was decreased and apoptosis was increased by Cav-1 silencing in a RANKLdependent manner (Figure 2a). BMMs with silenced Cav-1 showed reduced migration activity and abnormal morphology (Figures $2 \mathrm{~d}$ and e). These diverse effects of Cav-1 deficiency have been previously reported in other types of cells. ${ }^{18-20}$

M-CSF and RANKL have essential roles in osteoclast formation. ${ }^{1} \mathrm{M}$-CSF activates the receptor cFms, which autophosphorylates its own tyrosine residues. ${ }^{21,28}$ The activation of cFms triggers signaling pathways involving ERK1/2 and Akt for the proliferation and survival of osteoclast precursors. ${ }^{21}$ The importance of cFms signaling in osteoclastogenesis has been verified with cFms knockout mice that showed osteopetrosis. ${ }^{29}$ Similarly, RANKL-defective mice showed severe osteopetrosis with an absence of osteoclasts in their bone. ${ }^{30}$ RANKL stimulates the trimerization of RANK and TRAF6, which activates NFKB, Akt and mitogen-activated kinases including ERK1/2, JNK and p38. These signaling cascades have an important role in the induction of NFATc1., ${ }^{1,21}$ In our study, M-CSF- and RANKL-mediated MAPK and Akt signaling were attenuated by Cav-1 knockdown (Figure 3). Therefore, it seems that the reduced activation of the MAPK and Akt pathways leads to decreased NFATc1 induction, proliferation and migration, resulting in the suppression of osteoclastogenesis by Cav-1 knockdown.

Cav-1 directly interacts with membrane localized proteins via its scaffolding domain, ${ }^{22}$ and the interactions can alter signal transduction via several mechanisms. For example, caveolin-dependent endocytosis regulates the levels of surface proteins such as growth factor receptors, $\beta 1$ integrin and intracellular components associated with the plasma membrane. ${ }^{8,31}$ The degradation of Rac1 by Cav-1-dependent ubiquitination is important during cell migration. ${ }^{32}$ However, caveolin can also protect protein degradation by lysosomes, as shown by the promoted lysosomal targeting of dysferlin and insulin receptors by caveolin deficiency. ${ }^{8}$

We found that cFms co-immunoprecipitated with Cav-1 (Figure 4f), and the expression of cFms was decreased by Cav-1 knockdown at the protein level without any effect on its mRNA expression (Figures $4 \mathrm{a}$ and $\mathrm{b}$ ). This suggests that Cav-1 may affect the protein stability of cFms. Indeed, the silencing of Cav-1 led to the rapid degradation of the cFms protein (Figure 5a). The regulated intramembrane proteolysis process has been shown to be involved in the regulation of cFms protein levels. ${ }^{25}$ In this process, the receptor is first cleaved within the extracellular region. The second cleavage occurs in the transmembrane domain, and is induced by $\gamma$-secretase. Subsequently, cFms is subjected to ubiquitin-mediated degradation or targeted to lysosomes. ${ }^{25,33,34}$ In our study, neither the proteasome inhibitor nor the $\gamma$-secretase inhibitor blocked the degradation of cFms (Figures $5 \mathrm{~b}$ and $\mathrm{c}$ ). However, chloroquine treatment inhibited the degradation of cFms by Cav-1 knockdown (Figure $5 \mathrm{~d}$ ). These results indicate that Cav-1 protects the lysosomal degradation of $\mathrm{cFms}$.

The regulation of RANK expression by Cav-1 appeared to be at the transcriptional level, as Cav-1 knockdown reduced both RANK mRNA and protein levels (Figures $4 \mathrm{a}$ and $\mathrm{b}$ ). A previous report showed that RANK mRNA expression was induced by $\mathrm{M}-\mathrm{CSF}$ in the early stage of osteoclastogenesis. ${ }^{35}$ Therefore, it is possible that Cav-1 indirectly regulates RANK expression via its modulation of cFms protein stability. Detailed mechanisms and transcription factors involved in the RANK induction by cFms are yet to be elucidated, however.

\section{CONFLICT OF INTEREST}

The authors declare no conflict of interest.

\section{ACKNOWLEDGEMENTS}

This work was supported by the grant from the National Research Foundation of Korea (NRF-2014R1A2A1A10050406) to H-HK.

1 Takayanagi $\mathrm{H}$. Mechanistic insight into osteoclast differentiation in osteoimmunology. J Mol Med 2005; 83: 170-179.

2 Ikeda F, Matsubara T, Tsurukai T, Hata K, Nishimura R, Yoneda T. JNK/c Jun signaling mediates an anti-apoptotic effect of RANKL in osteoclasts. J Bone Miner Res 2008; 23: 907-914.

3 Lomaga MA, Yeh WC, Sarosi I, Duncan GS, Furlonger C, Ho A et al. TRAF6 deficiency results in osteopetrosis and defective interleukin-1, CD40, and LPS signaling. Genes Dev 1999; 13: 1015-1024.

$4 \mathrm{Kim} \mathrm{JH}$, Kim N. Regulation of NFATc1 in Osteoclast Differentiation. J Bone Metab 2014; 21: 233-241.

5 Nakashima T, Takayanagi $\mathrm{H}$. New regulation mechanisms of osteoclast differentiation. Ann N Y Acad Sci 2011; 1240: E13-E18.

6 Song I, Kim JH, Kim K, Jin HM, Youn BU, Kim N. Regulatory mechanism of NFATC1 in RANKL-induced osteoclast activation. FEBS Lett 2009; 583 : 2435-2440.

7 Razani B, Woodman SE, Lisanti MP. Caveolae: from cell biology to anima physiology. Pharmacol Rev 2002; 54: 431-467.

8 Parton RG, del Pozo MA. Caveolae as plasma membrane sensors, protectors and organizers. Nat Rev Mol Cell Biol 2013; 14: 98-112. 
9 Gratton JP, Bernatchez P, Sessa WC. Caveolae and caveolins in the cardiovascular system. Circ Res 2004; 94: 1408-1417.

10 Oakley FD, Smith RL, Engelhardt JF. Lipid rafts and caveolin-1 coordinate interleukin-1 beta (IL-1 beta)-dependent activation of NFkappaB by controlling endocytosis of Nox2 and IL-1beta receptor 1 from the plasma membrane. J Biol Chem 2009; 284: 33255-33264.

11 Syme CA, Zhang L, Bisello A. Caveolin-1 regulates cellular trafficking and function of the glucagon-like Peptide 1 receptor. Mol Endocrinol 2006; 20: 3400-3411.

12 Sengupta $\mathrm{P}$, Philip F, Scarlata S. Caveolin-1 alters $\mathrm{Ca}(2+)$ signal duration through specific interaction with the $\mathrm{G}$ alpha $\mathrm{q}$ family of $\mathrm{G}$ proteins. J Cell Sci 2008; 121(Pt 9): 1363-1372.

13 Buitrago C, Boland R. Caveolae and caveolin-1 are implicated in 1alpha,25 $(\mathrm{OH}) 2$-vitamin D3-dependent modulation of Src, MAPK cascades and VDR localization in skeletal muscle cells. J Steroid Biochem Mol Biol 2010; 121: 169-175.

14 Wang XM, Kim HP, Song R, Choi AM. Caveolin-1 confers antiinflammatory effects in murine macrophages via the MKK3/p38 MAPK pathway. Am J Respir Cell Mol Biol 2006; 34: 434-442.

15 Tsai TH, Chen SF, Huang TY, Tzeng CF, Chiang AS, Kou YR et al. Impaired Cd14 and Cd36 expression, bacterial clearance, and Toll-like receptor 4-Myd88 signaling in caveolin-1-deleted macrophages and mice. Shock 2011; 35: 92-99

16 Fu Y, Moore XL, Lee MK, Fernandez-Rojo MA, Parat MO, Parton RG et al. Caveolin-1 plays a critical role in the differentiation of monocytes into macrophages. Arterioscler Thromb Vasc Biol 2012; 32: e117-e125.

17 Lee YD, Yoon SH, Park CK, Lee J, Lee ZH, Kim HH. Caveolin-1 regulates osteoclastogenesis and bone metabolism in a sex-dependent manner. J Biol Chem 2015; 290: 6522-6530.

18 Bosch M, Mari M, Herms A, Fernandez A, Fajardo A, Kassan A et al. Caveolin-1 deficiency causes cholesterol-dependent mitochondrial dysfunction and apoptotic susceptibility. Curr Biol 2011; 21: 681-686.

19 Massimino ML, Griffoni C, Spisni E, Toni M, Tomasi V. Involvement of caveolae and caveolae-like domains in signalling, cell survival and angiogenesis. Cell Signal 2002; 14: 93-98.

20 Grande-Garcia A, Echarri A, de Rooij J, Alderson NB, Waterman-Storer CM, Valdivielso JM et al. Caveolin-1 regulates cell polarization and directional migration through Src kinase and Rho GTPases. J Cell Biol 2007; 177: 683-694.

21 Takayanagi H. Osteoimmunology: shared mechanisms and crosstalk between the immune and bone systems. Nat Rev Immunol 2007; 7: 292-304.

22 Okamoto T, Schlegel A, Scherer PE, Lisanti MP. Caveolins, a family of scaffolding proteins for organizing "preassembled signaling complexes" at the plasma membrane. J Biol Chem 1998; 273: 5419-5422.

$23 \mathrm{Ha} \mathrm{H}$, Kwak HB, Lee SK, Na DS, Rudd CE, Lee ZH et al. Membrane rafts play a crucial role in receptor activator of nuclear factor kappaB signaling and osteoclast function. J Biol Chem 2003; 278: 18573-18580.

24 Kopan R, Ilagan MX. Gamma-secretase: proteasome of the membrane? Nat Rev Mol Cell Biol 2004; 5: 499-504.
25 Wilhelmsen K, van der Geer P. Phorbol 12-myristate 13-acetate-induced release of the colony-stimulating factor 1 receptor cytoplasmic domain into the cytosol involves two separate cleavage events. Mol Cell Biol 2004; 24: 454-464.

26 Bonifacino JS, Traub LM. Signals for sorting of transmembrane proteins to endosomes and lysosomes. Annu Rev Biochem 2003; 72: 395-447.

27 Alwan HA, van Zoelen EJ, van Leeuwen JE. Ligand-induced lysosomal epidermal growth factor receptor (EGFR) degradation is preceded by proteasome-dependent EGFR de-ubiquitination. J Biol Chem 2003; 278: 35781-35790.

28 Ross FP. M-CSF, c-Fms, and signaling in osteoclasts and their precursors. Ann N Y Acad Sci 2006; 1068: 110-116.

29 Dai XM, Ryan GR, Hapel AJ, Dominguez MG, Russell RG, Kapp S et al. Targeted disruption of the mouse colony-stimulating factor 1 receptor gene results in osteopetrosis, mononuclear phagocyte deficiency, increased primitive progenitor cell frequencies, and reproductive defects. Blood 2002; 99: 111-120.

30 Kong YY, Yoshida H, Sarosi I, Tan HL, Timms E, Capparelli C et al. OPGL is a key regulator of osteoclastogenesis, lymphocyte development and lymphnode organogenesis. Nature 1999; 397: 315-323.

31 Di Guglielmo GM, Le Roy C, Goodfellow AF, Wrana JL. Distinct endocytic pathways regulate TGF-beta receptor signalling and turnover. Nat Cell Biol 2003; 5: 410-421.

32 Nethe M, Anthony EC, Fernandez-Borja M, Dee R, Geerts D, Hensbergen PJ et al. Focal-adhesion targeting links caveolin-1 to a Rac1-degradation pathway. J Cell Sci 2010; 123(Pt 11): 1948-1958.

33 Glenn G, van der Geer P. CSF-1 and TPA stimulate independent pathways leading to lysosomal degradation or regulated intramembrane proteolysis of the CSF-1 receptor. FEBS Lett 2007; 581: 5377-5381.

34 Lee PS, Wang Y, Dominguez MG, Yeung YG, Murphy MA, Bowtell DD et al. The $\mathrm{Cbl}$ protooncoprotein stimulates CSF-1 receptor multiubiquitination and endocytosis, and attenuates macrophage proliferation. EMBO J 1999; 18: 3616-3628.

35 Arai F, Miyamoto T, Ohneda O, Inada T, Sudo T, Brasel K et al. Commitment and differentiation of osteoclast precursor cells by the sequential expression of $\mathrm{C}-\mathrm{Fms}$ and receptor activator of nuclear factor kappaB (RANK) receptors. J Exp Med 1999; 190: 1741-1754.

(c) (1) () $\odot$ This work is licensed under a Creative Commons Attribution-NonCommercial-NoDerivs 4.0 International License. The images or other third party material in this article are included in the article's Creative Commons license, unless indicated otherwise in the credit line; if the material is not included under the Creative Commons license, users will need to obtain permission from the license holder to reproduce the material. To view a copy of this license, visit http://creativecommons.org/licenses/by-nc-nd/4.0/ 